\title{
Food security and morbidity of elderly in disadvantaged rural Bangladesh
}

\author{
M. A. Quddus ${ }^{1 *}$ and S. Bauer ${ }^{2}$ \\ ${ }^{1}$ Department of Agricultural Statistics, Bangladesh Agricultural University, Mymensingh-2202, Bangladesh and \\ ${ }^{2}$ Institute of Project and Regional Planning, Justus-Liebig University, Giessen, Germany, *E-mail: \\ aqdds4815@yahoo.com
}

\begin{abstract}
The study was undertaken to assess the food consumption level, prevalence of food insecurity and health status of elderly in the disadvantaged rural area of Bangladesh. Data were collected from fifteen villages in three vulnerable regions (river-flooded, hilly and coastal) through self-completed questionnaire. Descriptive statistics of sociodemographic characteristics of 282 households, food frequency and overall health status of elderly were measured. Economic, demographic and some other household characteristic factors influencing food insecurity of elderly people was estimated using binary logistic regression model. Socio-demographic factors influencing morbidity of elderly people were estimated using Chi-square statistics. Socioeconomic conditions of the studied areas were poor and they spent above $83 \%$ of their income for food. Rice, wheat, pulses and vegetables were the highly consumed and fruits and sweets were the less consumed foods by the elderly people. One-fourth and two-third of the elderly people had eaten fish and meat, respectively less than a week. Food insecurity was inversely associated with household income and level of education of elderly people and positively associated with number of household member. Food security was 3.5 times more likely to the oldest elder ( $\geq 75$ years) as compared with older elder (< 75 years). Elderly people of age group 75 years and over were more prevalence of morbidities and $23.8 \%$ elders were suffering from severe morbidity. Also they suffered from treatment facilities. Higher age, low income, food insecurity and anxiety were the major causes of their morbidity. No significant morbidity differentials existed among different sexes, farm size and study locations. Proper intervention programs should be designed and implemented to control the prevalence of health and food availability for the elderly.
\end{abstract}

Key words: Food security, Elder Morbidity, Health status, VGF card

\section{Introduction}

In most gerontological literature, people above 60 years of age are considered as "old" and taken to be the "elderly" segment of the population of a country. Population above the age of sixty has reached over 7.2 million in 2005, percentage was nearly $6 \%$ in 2000 and it will be increase to 8.4 and $16 \%$ in 2025 and 2050, respectively in Bangladesh (Saleheen, 2005). Most of the older people in Bangladesh, particularly the poor, are not defined old according to chronological age. In general older people are defined "old" according to physical characteristic and limitations that affect their ability to function in daily life in both household and income generation work (Saleheen, 2005). The common sentiment of Bangladeshi people is that elders are unable to earn money, are dependent on their families for survival, and therefore, are a burden. In rural areas, many younger people do no value the contributions of older people to the family and community.

Nutritional evaluations indicate that older persons are at significant risk for poor access to nutritionally adequate diets and that food assistance programmes are not keeping pace with their needs (Codispoti and Bartlett, 1994). Food insufficiency may affect metabolic markers of poor nutrition, especially in high risk elder persons. Malnutrition is a risk factor for several specific health conditions common in older persons. For example, malnourished older persons are at greater risk for osteoporosis, caused by inadequate calcium intake, which leads to increased risk of hip fracture (Ensrud et al., 2000). Therefore, investigating the health consequences of food insufficiency may lead to a better understanding of the public health risks associated with inadequate nutritional services to the elderly (Klesges et al., 2001). In this study, we sought to increase our knowledge of food sufficiency problems by reporting the food frequency and the prevalence of food insecurity of elderly in the disadvantaged rural Bangladesh. Low level household income, a large number of family members or number of children, lack of education and some other socio-demographic factors are the main constraints on food security of elderly people in Bangladesh. Thus, affects of these factors are needed for the development of policies and programmes to ensure their food security. 
The disease state of an individual or the incidence of illness in a population is termed as morbidity. Elderly persons experience a higher rate of morbidity and mortality than their counterparts (Khaw, 1997). Perceived health and chronic illness are major elements of health status in the elderly, because perceived health declines with age and chronic health problems increase with age. Age, household income, household food availability, depression are the vital factors affecting the morbidity of elders. Morbidity is at the extremes of age above 60 years (Kutty and Thankapoan (1994) and education is inversely related to morbidity (Duraiswamy, 1998). Therefore, evaluations of the related factors are required to improve the delivery of health care to the elderly. In the course of growing old, in addition to declining health, some elderly persons are exposed to the loss of significant relation, separation from children, reduced income status, or identity (Chi and Chow, 1997) and these losses may have detrimental effects on an elderly person's health exacerbating psychosocial, behavioural, and environmental risk factors for poor health in the later years of their lives (Chow and Chi, 1997; Rake, 1999; Williams, 1996). Many studies have documented that greater economic resources correlate with lower rate of morbidity and mortality (Blane, 1995; Blane et al., 1997; Fraser et al, 2001). Mostafa and van Ginneken (2000) found that in Bangladesh, elderly persons of high socioeconomic status were likely to be longer than those of lower socioeconomic status. Furthermore, elderly persons of higher social position are less likely to be disabled and need care (Melzer et al., 2000).

Hence, a study was carried out in the disadvantaged rural areas in Bangladesh with the aim of evaluating household's socio-demographic characteristics, frequency of major foods intake, prevalence of their food insecurity, and health and morbidity status of elderly people. The study will provide a better understanding of measure food insecurity level in disadvantaged poor elderly people and provide information to reduce food insecurity of elders. This study will reflect an exploratory investigation, the strongest empirical evidence and expands knowledge of the relative importance among the elderly heads and may lead to a better understanding of the public assistance requirement to the elderly. The specific objectives were: (i) to know the household characteristics and reception of public assistance; (ii) to investigate the food intake level of elderly; (iii) to determine the factors affecting food insecurity; and (iv) to make an association between morbidity status of elderly people with their socio-demographic and other related factors.

\section{Materials and Methods}

\section{Study design and data collection}

The study was conducted in three ecologically contrasting disadvantaged regions (river flooded, hilly/ forest and coastal) of the country. The regions were selected purposively on the basis of the nature and vulnerability. For the first region, Brahmaputra river-flooded area in Mymensingh district was chosen and two different sub-districts Mymensingh sadar and Gauripur were selected as two strata. Similarly, for the second region, two different districts were chosen, Nalitabari sub-district under Sherpur district as hilly area and Madhupur sub-district under Tangail district was selected as forest area. Finally, Dumki subdistrict under Patuakhali district was selected as coastal area. Thus, three regions were divided into five strata. Three adjacent villages were selected from each stratum. The next stage was a selection of households using simple random sampling technique. A complete listing of households residing in each selected village was carried out. The lists of households obtained were used as the frame of sampling. Households having at least an elder were eligible to be interviewed and 20 households were targeted to interview from each village (villages are quite small).

A questionnaire was developed based on the objectives of the research. A qualified primary healthcare person was recruited and trained to conduct the field survey over six months and researcher shared in most of the time. Questionnaire was self-completed by the field surveyor with elderly person and or household head and or housewife. The questionnaire included sex, age and education of the elders; family member, farm size, per capita income of households and elderly allowance (if received). The questionnaire also included the frequency level of food intake, general health condition and morbidity status of elders. A set of food frequency questionnaires was developed for elders. Subjects were asked how often they ate the general meals and what kinds of foods were included in the meals. Food frequency categories used were more than once a day, once a day, 4-7 times a week, 1-3 times a week, at least once a month, less than once a month. The six-item short form of food security scale was developed in the form described by Blumberg et al. (1999). The interview took place in the participants' home, and informed consent was acquired. Household head or elderly people were asked the questions. A few numbers of households were absent and some cases household head or housewife refused to interview and finally, a few number of questionnaire found to incomplete information. Thus, out of 300 target households, 282 completed questionnaires were taken for analysis. Data were collected from January to June 2009. 


\section{Measurement}

The six-item short form of questions were: (i) elderly people often or sometimes relied on a few kinds of low-cost food or imbalanced meal because they were running out of money to buy food; (ii) the elderly were not eating enough because they just couldn't afford enough food; (iii) they cut the size of meals because there was not enough money for food; (iv) they were skipping meal once or twice in most of the days; (v) they were hungry but they couldn't afford more food; and (vi) elderly were not eating for whole day. Each question had four response options: never, rarely, sometimes and often, which were coded in order of increasing frequency from 0-3. An elderly was classified as food insecure if the household head or elderly reported experiencing any of the six conditions within the recall period (i.e. if the answer to any of the questions was rarely, sometimes or often), otherwise he or she was classified as food secure.

To classify physical health condition of the elderly, a single question was asked "how do you think about your health" with 4 possible responses: very good, good, fair and poor. Anxiety (depression) is a major psychological disorder that affects the quality of the elderly (Sun et al., 2007). Thus, status of anxiety was assessed by examining level of anxiety in the study population. Self-rated severity of diseases (morbidity) was also assessed with 3 possible responses: (1) severe morbidity if any chronic disease including hypertension, cardiovascular diseased, diabetes, stroke, etc; (2) moderate morbidity if elder had been suffering from any mild or moderate diseases; and (3) healthy if no moderate or severe diseases or no mild diseases for long time.

\section{Statistical analysis}

Binary logistic regression analysis was carried out to study the chances of food insecurity. In this analysis, food insecurity status was considered as dependent variable (dichotomous: 1 for food insecure elder and 0 for food secured elder). Independent variables were categorical and they were the study areas, sex, age category, education level of elders, number of people in the household, farm size and income category of households, current use of elderly allowance, etc. Odds ratios for outcome categories taking into account the ordering of outcomes categories and 95\% confidence intervals were calculated to test the significance of odds ratios. Association of morbidity status with socio-demographic and other related factors was estimated from contingency table and Chi-square statistic was used to verify the significance of associations. Data analysis was carried out using the SPSS for Windows software version 11.5. Binary logistic regression analysis was carried out to determine the likelihood ratio of socio-demographic factors with food insecurity of elderly people. The logit function was as follows:

$$
\operatorname{Logit}\left(E\left(Y_{i}\right)\right)=\log \left(\frac{p_{i}}{1-p_{i}}\right)=\text { Intercept }+\beta_{1} X_{1}+\beta_{2} X_{2}+\beta_{3} X_{3}+\beta_{4} X_{4}+\beta_{5} X_{5}+\beta_{6} X_{6}+\beta_{7} X_{7}+\beta_{8} X_{8}+U_{i}
$$

Where $E\left(Y_{i}\right)=p_{i}$ implies that the expected value of $\left(Y_{i}\right)$ equals the probability that $Y_{i}=1$;

$X_{1}=$ Study area; 0 for river-flooded area, 1 for Hills and 2 for coastal area;

$X_{2}=$ Sex of elder; 0 for male and 1 for female;

$X_{3}=$ Age of elder; 1 for elderly people of 75 years and above and 0 otherwise;

$X_{4}=$ Level of education of elders; 0 for illiterate, 1 for can read and write only and 2 for having formal education;

$X_{5}=$ Number of people in the household; 1 for 1 to 5 members and 0 otherwise;

$X_{6}=$ Farm size of household; 2 for landless, 1 for marginal and 0 otherwise;

$X_{7}=$ Having elderly allowance; 1 for having elderly allowance and 0 otherwise;

$X_{8}=$ Level of income; 1 for below average income and 0 otherwise;

$\beta_{1,} \beta_{2}, \beta_{3,} \beta_{4,} \beta_{5}, \beta_{6}, \beta_{7}, \beta_{8}$ are the coefficients;

$U_{i}$ is the error term; and

$$
\frac{p_{i}}{1-p_{i}}=\text { Odds ratio associated with each predictor value. }
$$




\section{Results and Discussion}

\section{Household Characteristics and Reception of Public Assistance}

Table 1 presents the average features of household characteristics according to income classes and study locations. Family size, number of children and school going children per household has an increasing trend with the increase of income of the family and the average size was $6.3,2.5$ and 1.1, respectively. There was no far difference of these three measures in three study locations. The average landholdings was 0.20 hectors (standard deviation 0.303 and range $0-2.43$ hectors). The households of above average income had land holdings 2.4 times and per capita bedroom 1.5 times higher than the households of below average income. Both these characteristics were better in hills and forests as compared with river-flooded and coastal regions. Similarly, per capita income of the households of below average income group was $40 \%$ of the above average income group and this figure was very low in the river-flooded area as compared with other two areas. Per capita food expenditure of the low-income group was half that of the high-income group and this figure was less in the river-flooded area compared to the other areas. They spent major portion of their income for food and the ratio of food cost to income was higher for the low-income group as compared with high-income group.

Public assistance for the poor people in the vulnerable regions of Bangladesh is devoted under the programme of 'Social Safety Nets Programmes (SSNP). Elderly allowance, vulnerable group feeding (VGF) and subsidy to buy rice and wheat are the main sources of public assistance. In this study, out of 282 surveyed households 61 i.e., about $21.6 \%$ households were found to receive public assistance whereas $11 \%$ households received elderly allowance equalizing Tk.250 per month per household. About $7 \%$ households had a VGF card and each of them received 5 to 30 kilograms rice (average 19.3 kilograms per month) but it was missed once or twice per year. Only 5 households received the price subsidiary for rice only and each of them received rice up to 50 to $60 \%$ subsidy. In $2005,13.06 \%$ of the households received benefits from SSNP with $15.64 \%$ households in rural areas and $5.45 \%$ in urban areas and the average amount were received from old age allowance Tk.1429 and from VGF Tk.439. Among the households covered by SSNP, the highest proportion benefits from VGF $33.86 \%$ followed by old age pension $17.91 \%$ and VGD $17.59 \%$ (HIES, 2005). According to opinion of some respondents, public assistance programmes were helpful for the poor, but selection of households was not proper, especially, for VGF cards and the amount of elderly allowance were inadequate.

Table 1. Average features of household characteristics according to income classes and locations

\begin{tabular}{|l|c|c|c|c|c|c|}
\hline \multirow{2}{*}{ Characteristics } & \multicolumn{2}{|c|}{ Income Groups } & \multicolumn{3}{|c|}{ Locations } \\
\cline { 2 - 6 } & $\begin{array}{c}\text { Below } \\
\text { Average }\end{array}$ & $\begin{array}{c}\text { Above } \\
\text { average }\end{array}$ & $\begin{array}{c}\text { River } \\
\text { Flooded }\end{array}$ & $\begin{array}{c}\text { Hills/ } \\
\text { Forest }\end{array}$ & Coastal & \\
\hline Family Size & 6.1 & 7.1 & 6.2 & 6.4 & 6.4 & 6.3 \\
\hline Number of Children / HH & 2.5 & 2.7 & 2.6 & 2.7 & 2.3 & 2.5 \\
\hline Number of School Going Child / HH & 1.0 & 1.5 & 1.0 & 1.25 & 1.2 & 1.1 \\
\hline Land / HH (ha) & 0.15 & 0.36 & 0.19 & 0.23 & 0.19 & 0.20 \\
\hline Size of Bedroom per Capita (sq. m) & 5.0 & 7.6 & 5.3 & 6.2 & 5.9 & 5.7 \\
\hline Income per Month / HH (Taka) & 3030 & 8956 & 4035 & 4880 & 5095 & 4540 \\
\hline Income per Month per Capita (Taka) & 521 & 1308 & 615 & 827 & 801 & 721 \\
\hline Food Expenditure / HH (Taka) & 2588 & 5981 & 2918 & 3745 & 4111 & 3453 \\
\hline Food Expenditure per Capita (Taka) & 444 & 892 & 467 & 628 & 650 & 558 \\
\hline Ratio of Food Cost and Income & 0.86 & 0.74 & 0.83 & 0.82 & 0.85 & 0.83 \\
\hline
\end{tabular}

Source: Field Survey, 2009

Note: $\mathrm{HH}$ means household 


\section{Food Intake Level}

Rice, wheat, pulses and vegetables were the highly consumed food of the elderly people in the study areas. About $23.4 \%$ elderly had eaten rice and or wheat once a day and no any elder had eaten less than once a day. About $27.3 \%$ elderly had eaten pulses in their meals once a day and $17.7 \%$ of them had eaten 3 to 7 times per week (Table 2). They had eaten leafy vegetables more frequently than other vegetables. Moderately consumed foods of the elderly in the vulnerable regions were fish, meat, eggs and milk. About $16.3 \%$ elderly had eaten fish every day, $56.7 \%$ had eaten 1 to 7 times per week and $23.8 \%$ had eaten 1 to 4 times in a month. No elderly had eaten meat every day, $30.8 \%$ of them had eaten 1 to 7 times in a week and $69.2 \%$ of them had eaten meat less than a week. They had eaten eggs less frequently than meat. Most of the elderly had drunk milk a few times monthly or a less than a month. A little proportion of elderly had never eaten protein foods. The elderly people of the vulnerable region had eaten sweets and fruits in very rare.

Table 2. Frequency distribution of 10 major food items according to consumption level of elders

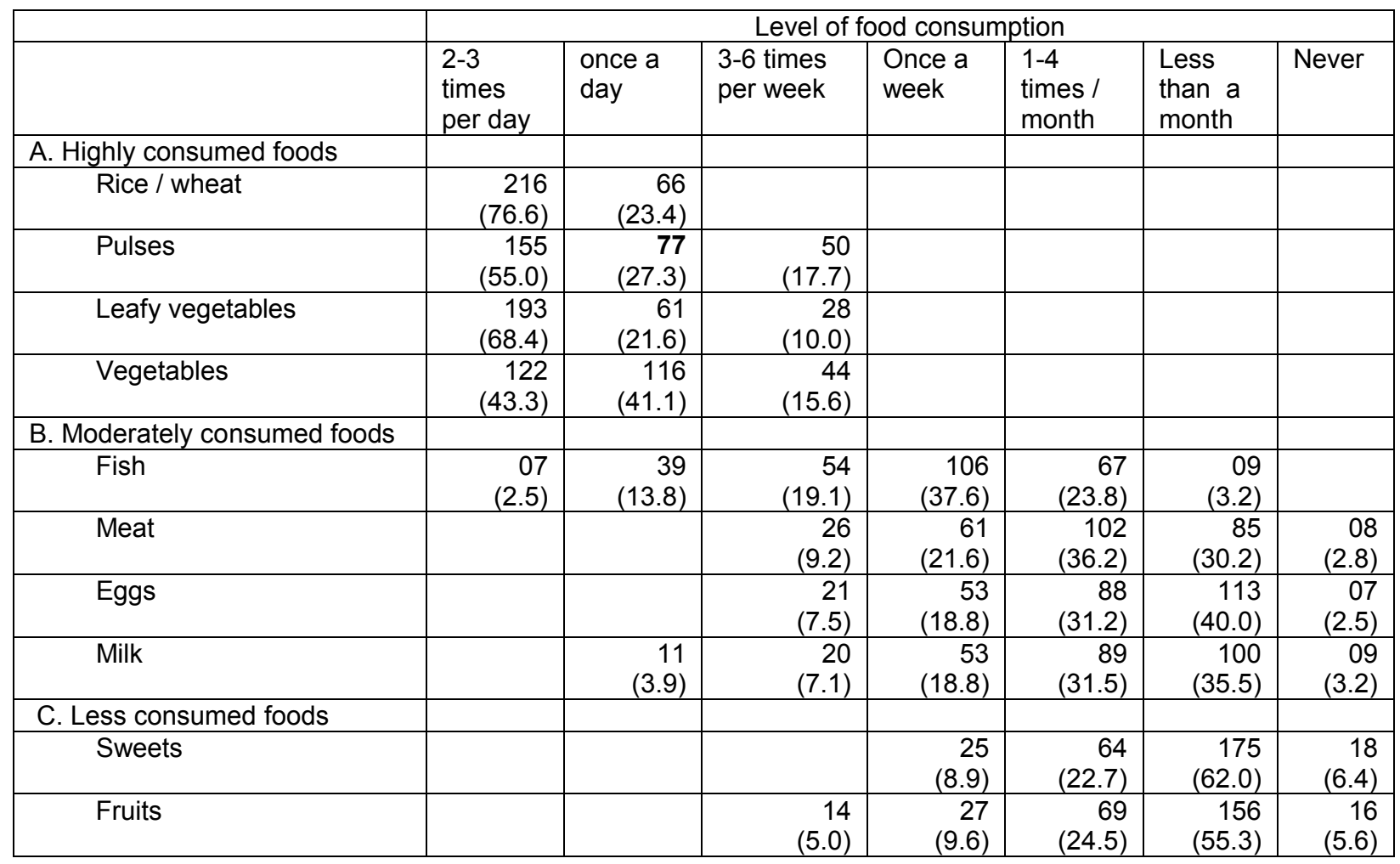

Source: Field Survey, 2009

Figures in the parentheses indicate percent

Self-reported frequency of eating various foods is a simple form of dietary assessment (Schlettwein-Gsell, 1989 and Natarajan et al., 1993), but it does not allow accurate calculation of daily nutrient intake which could be compared with international recommendations. The consumption frequencies of protein foods such as meat, fish and eggs in most of the participants were not good, although a large proportion did not drink milk $(38.7 \%)$ and fruits $(61 \%)$ in a month. In the present study, inadequate intake of protein foods and fruits was associated with unfavourable economic conditions and low purchasing power. The overall food consumption patterns showed a low frequency of fruit and milk intake and these results followed by Olayiwola (2009) and Kabir et al. (2010), respectively. Low level of schooling can also influence consumption due to the adoption of inadequate dietary habits and due to the higher frequency of related problems (Seabra, 2007). 


\section{Prevalence and Factors Affecting Food Insecurity}

Table 3 shows the prevalence of food insecurity according to socio-demographic and household characteristics of the elderly people. River-flooded area was more food insecure as compared to hills/ forest and coastal areas. The prevalence of food insecurity was higher among elderly female compared to elderly male and oldest elders (75 years and above) than older elders (60-74 years). The prevalence of food insecurity was higher $(78 \%)$ among elderly people having more than 5 people in the household compared to elderly people having 1 to 5 people in the households (59\%). Food insecurity was significantly associated with the study location, level of education of elderly people, number of people in household, farm size of household and level of household income.

Table 3. Prevalence of food insecurity of elderly people and results of logistic regression analysis

\begin{tabular}{|c|c|c|c|c|c|c|}
\hline Variables & Category & $\begin{array}{r}\text { Number in } \\
\text { category }\end{array}$ & $\begin{array}{l}\text { Insecure } \\
\%\end{array}$ & $\begin{array}{l}\text { Odds } \\
\text { Ratio }\end{array}$ & $95 \% \mathrm{Cl}$ & $p$-values \\
\hline \multirow[t]{3}{*}{ Study location } & River-Flooded* & 132 & 83 & & & \\
\hline & Hills/ Forests & 78 & 64 & 0.26 & $0.11-0.64$ & 0.003 \\
\hline & Coastal & 72 & 61 & 0.39 & $0.16-0.93$ & 0.034 \\
\hline \multirow[t]{2}{*}{ Gender } & Male* $^{*}$ & 159 & 70 & & & \\
\hline & Female & 123 & 76 & 1.08 & $0.55-2.14$ & 0.813 \\
\hline \multirow[t]{2}{*}{ Age group } & $60-74$ year* $^{*}$ & 195 & 68 & & & \\
\hline & 75 years and above & 87 & 90 & 3.54 & $1.50-8.36$ & 0.004 \\
\hline \multirow[t]{3}{*}{ Level of education } & Illiterate* $^{*}$ & 169 & 77 & & & \\
\hline & Can read and write only & 71 & 66 & 0.79 & $0.35-1.77$ & 0.572 \\
\hline & Having formal education & 42 & 62 & 0.33 & $0.12-0.92$ & 0.033 \\
\hline \multirow{2}{*}{ Number of people in $\mathrm{HH}$} & 1 to 5 members ${ }^{*}$ & 96 & 59 & & & \\
\hline & More than 5 & 186 & 78 & 3.32 & $1.66-6.64$ & 0.001 \\
\hline \multirow[t]{3}{*}{ Farm size of Household } & Small /Medium (0.40 ha +$)^{*}$ & 47 & 55 & & & \\
\hline & Marginal $(0.05-0.40 \mathrm{ha})$ & 135 & 73 & 1.83 & $0.80-4.19$ & 0.152 \\
\hline & Landless (<= $0.05 \mathrm{ha})$ & 100 & 79 & 2.61 & $1.01-6.75$ & 0.047 \\
\hline \multirow[t]{2}{*}{ Having elderly allowance } & No* & 248 & 69 & & & \\
\hline & Yes & 34 & 91 & 2.97 & $0.67-13.10$ & 0.151 \\
\hline \multirow[t]{2}{*}{ Level of income } & Above average income ${ }^{*}$ & 84 & 42 & & & \\
\hline & Below average income & 198 & 85 & 9.15 & $4.44-18.86$ & 0.001 \\
\hline
\end{tabular}

Source: Field Survey, 2009

Note: $\mathrm{HH}$ - household; $\mathrm{Cl}$ - confidence interval and * indicates reference category

The prevalence of food insecurity was higher among elderly people receiving elderly allowance compared with elderly people not receiving elderly allowance. Because they are very poor; and poor amount of allowance are not sufficient to reduce food insecurity. Furness et al. (2005) found similar pattern of food insecurity prevalence in case of receiving public assistance in Lose Angeles country. Low income, illiteracy and higher family size were strongly associated with food insecurity support the need to increase availability and acceptability of services to those at high risk for problems of food access such as elders having very low household income. III health is a major factor in the ecology of food insecurity in rural areas and hence the provision of health care at an affordable cost is central to promoting food security in rural setting are needed (Olson, 2005). The present study showed higher food insecurity status of aged persons in compare to other studies (Frongillo et al., 2003 and Gulliford et al., 2003) because the study sample was from highly disadvantaged rural areas and very low socioeconomic families in Bangladesh Food insecurity affects people of all ages, but this study is of particular concern of aged person only.

Odds ratios illustrate that food insecurity was $8.6 \%$ more likely to female as compared to male (Table 3 ). Food insecurity was 3.5 times more likely to the oldest elders (OR=3.54; $95 \% \mathrm{Cl}=1.50-8.36)$ as compared to older elders. Food insecurity was $21 \%$ less likely among the elders who could read and write only and $67 \%$ less likely (significantly) among the elders having formal education as compared to illiterate elders. Food insecurity was significantly higher ( $\mathrm{OR}=3.32 ; 95 \% \mathrm{Cl}=1.66-6.64)$ among elderly people having 6 or more members in the household as compared to elders having 1 to 5 members in the household. Similarly, elders of the household having below average monthly income were significantly 
higher food insecure as compared to elders' household having above average income. Food insecurity was significantly higher $(\mathrm{OR}=2.61 ; 95 \% \mathrm{Cl}=1.01-6.75)$ among elderly people having landless as compared to elders having small/ medium farm holdings. Elders having elderly allowance were more food insecure than the elders having no elderly allowance.

\section{Morbidity status of elders}

Self-assessed health status of most of the elders was good $(33 \%)$ or fair $(44 \%)$ and there was no far difference between men and women. About $50 \%$ elderly people had suffered from low level of anxiety and $30.1 \%$ elderly people had suffered from high or extremely high level of anxiety. About $23.8 \%$ elders were suffering from severe morbidity of which men $26.4 \%$ and women $20.3 \%$ whereas, $48.9 \%$ were suffering from moderate morbidity and $27.3 \%$ of them were healthy (Table 4 ). About $85 \%$ of the rural elders could not take treatment properly due to lack of money or absence of treatment facilities near them. Physical health condition of most of the elders was good or fair and the majority of the elderly indicated that they had reduced ability to function. There was no much difference in health conditions among the males and females but males were much better in respect to very good health. Having no or low anxiety was higher for female than that of male whereas high and extreme high anxiety was higher for male interpret that males are more responsible for their family maintenance. A large portion of elderly people could not take treatment because of lack of money and absence of treatment facilities easily accessible.

Table 4. Percentage distribution of elder's overall health and treatment conditions

\begin{tabular}{|c|c|c|c|}
\hline \multirow{2}{*}{$\begin{array}{l}\text { Health / Treatment } \\
\text { Characteristics }\end{array}$} & \multicolumn{3}{|c|}{ Percentage value } \\
\hline & $\begin{array}{r}\text { Men } \\
\mathrm{N}=159\end{array}$ & $\begin{array}{r}\text { Women } \\
\mathrm{N}=123\end{array}$ & $\begin{array}{r}\text { All } \\
\mathrm{N}=282\end{array}$ \\
\hline \multicolumn{4}{|c|}{ Self-assessed health status } \\
\hline Very Good & 6.3 & 5.7 & 6.0 \\
\hline Good & 33.3 & 32.5 & 33.0 \\
\hline Fair & 44.7 & 43.1 & 44.0 \\
\hline Poor & 15.7 & 18.7 & 17.0 \\
\hline \multicolumn{4}{|l|}{ Level of Anxiety } \\
\hline No & 15.7 & 25.2 & 19.9 \\
\hline Low & 42.8 & 59.3 & 50.0 \\
\hline High & 29.6 & 13.0 & 22.3 \\
\hline Extreme & 11.9 & 2.5 & 7.8 \\
\hline \multicolumn{4}{|l|}{ Morbidity } \\
\hline Severe & 26.4 & 20.3 & 23.8 \\
\hline Moderate & 51.6 & 45.5 & 48.9 \\
\hline Healthy & 22.0 & 34.2 & 27.3 \\
\hline \multicolumn{4}{|l|}{ Level of Treatment } \\
\hline Good & 13.8 & 15.5 & 14.5 \\
\hline Fair & 39.6 & 40.7 & 40.1 \\
\hline Poor & 32.7 & 31.7 & 32.3 \\
\hline No & 13.8 & 12.9 & 13.1 \\
\hline
\end{tabular}

Source: Field Survey, 2009

Results of association between morbidity level of elderly people and their socioeconomic factors are shown in Table 5. The result shows that age group, level of food security, level of anxiety and household income category were significantly associated with morbidity level. There were no significant morbidity differentials among different sexes, farm size and study locations and they were not major factors in determining morbidity status in the study area. In this analysis, it shows that illiterate elders had highest morbidity level compared to other groups, elderly having below average household income had higher morbidity compared to above average income and elders aged 75 years and older are more likely to report illness than that of aged 60-74 years. Thus, it may suggest that these three factors (age, income and education) are the significant determinants of morbidity status of rural elderly people i.e. elders of 
above age but illiterate and low earning families had a greater risk to severe morbidity. Similarly, food insecurity and higher level of anxiety had a significant greater risk to severe morbidity. The key factors affecting the health profile of the elderly were incidence and timing of onset of chronic illnesses and disability and levels of mortality (Pilloni et al., 2000). Physical health condition, level of anxiety and morbidity of elders were self-reported by the subjects and these were focused on lifestyle-related illness, those might affect the accuracy of information and weaken the effect of level of morbidity. As this study is a cross-sectional design, it is difficult to draw conclusions about any casual relations between morbidity and the factors identified in the study. All findings need to be confirmed in a longitudinal study.

Table 5. Demographic, economic, health and food security characteristics of the respondents according to level of morbidity

\begin{tabular}{|c|c|c|c|c|c|c|}
\hline \multirow[t]{2}{*}{ Characteristics } & \multicolumn{3}{|c|}{ Morbidity } & \multirow[t]{2}{*}{ Total (\%) } & \multirow[t]{2}{*}{ Value of $x^{2}$} & \multirow[t]{2}{*}{$p$-value } \\
\hline & $\begin{array}{c}\text { Healthy } \\
n=77\end{array}$ & $\begin{array}{c}\text { Moderate } \\
n=138\end{array}$ & $\begin{array}{l}\text { Severe } \\
n=67\end{array}$ & & & \\
\hline \multicolumn{5}{|l|}{ Gender } & \multirow{3}{*}{0.013} & \multirow{3}{*}{0.99 .3} \\
\hline Men & 43 & 78 & 38 & $159(56.4)$ & & \\
\hline Women & 34 & 60 & 29 & $123(43.6)$ & & \\
\hline \multicolumn{5}{|l|}{ Age } & \multirow{3}{*}{48.095} & \multirow{3}{*}{0.001} \\
\hline $60-74$ years & 71 & 97 & 27 & $195(69.1)$ & & \\
\hline Above 74 years & 06 & 41 & 40 & $87(30.9)$ & & \\
\hline \multicolumn{5}{|l|}{ Level of education } & \multirow{4}{*}{3.346} & \multirow{4}{*}{0.502} \\
\hline Illiterate & 44 & 87 & 38 & $169(59.9)$ & & \\
\hline Can read and write & 24 & 31 & 16 & $71(25.2)$ & & \\
\hline Literate & 9 & 20 & 13 & $42(14.9)$ & & \\
\hline \multicolumn{5}{|l|}{ Level of food security } & \multirow{3}{*}{52.487} & \multirow{3}{*}{0.001} \\
\hline Food secure & 45 & 29 & 5 & 79 (28.0) & & \\
\hline Food insecure & 32 & 109 & 62 & $203(72.0)$ & & \\
\hline \multicolumn{5}{|l|}{ Anxiety } & \multirow{4}{*}{82.496} & \multirow{4}{*}{0.001} \\
\hline No & 29 & 20 & 7 & $56(19.8)$ & & \\
\hline Low & 42 & 86 & 13 & 141(50.0) & & \\
\hline High & 6 & 32 & 47 & $85(30.2)$ & & \\
\hline \multicolumn{7}{|l|}{ Family size } \\
\hline$=<5$ & 33 & 38 & 25 & $96(34.0)$ & 5.583 & 0.061 \\
\hline$>5$ & 44 & 100 & 42 & $186(66.0)$ & & \\
\hline \multicolumn{7}{|l|}{ Farm size } \\
\hline Small / Medium & 12 & 26 & 9 & $47(16.7)$ & 3.151 & 0.553 \\
\hline Marginal & 36 & 61 & 38 & $135(47.9)$ & & \\
\hline Landless & 29 & 51 & 20 & $100(35.4)$ & & \\
\hline \multicolumn{7}{|l|}{ Household Income category } \\
\hline Above average income & 30 & 41 & 13 & $84(29.8)$ & 6.699 & 0.035 \\
\hline Below average income & 47 & 97 & 54 & $198(70.2)$ & & \\
\hline \multicolumn{7}{|l|}{ Area of residence } \\
\hline River flooded & 31 & 61 & 40 & $132(46.8)$ & 7.084 & 0.132 \\
\hline Hills/ Forests & 22 & 40 & 16 & $78 \quad(27.7)$ & & \\
\hline Coastal & 24 & 37 & 11 & $72(25.5)$ & & \\
\hline
\end{tabular}

Source: Field Survey, 2009

\section{Conclusion}

Findings of this paper confirm that food insecurity is an important public health and equity issue among elderly people in the disadvantaged rural Bangladesh that can be addressed through implementing appropriate income and social support policies. These results suggest that much more attention needs to be placed on reducing household poverty to increase food resources for the elderly people. The programmes should be directed to control health problems associated with inadequate or improper dietary intake. However, nutrition education efforts may focus on improving food diversity with targeting rural elderly. The rate of elderly allowance should be increased and assistance through VGF cards and 
food subsidy for elderly people should be provided in regular basis. Further investigations are needed on the specific health problems that the elderly have and the extent of their inability to function. Assessment of the economic and physical reasons for these changes would be necessary prior to designing any national intervention. Also, health and nutrition intake of this population should be further investigated relative to life experiences before national recommendations are developed. In addition to our preliminary findings, further evaluation of the relations between food insufficiency and nutritional status may help to improve methods to ensure adequate food access and dietary intake in older persons.

\section{Acknowledgment}

The authors are thankful to the Deutscher Akademischer Austauschdienst (DAAD) for financial support.

\section{References}

Blane, D. 1995. Social determinants of health: Socioeconomic status, social class, and ethnicity. Ageing and Society, p. 33-54.

Blane, D., Bartley M, and G.D. Smith G.D. 1997. Disease aetiology and materialist explanations of socioeconomic mortality differentials. European J. Public Health, 74: 385-391.

Blumberg, S.J., Bialostosky K., Hamilton W.I. and Briefel R.R. 1999. The effectiveness of a short form of the household food security scale. Am. J. Public Health, 89(8): 1232-1234.

Chi, I. and Chow N.S.W 1997. Housing and family care for the elderly in Hong Kong. Ageing International, 23: 65-77.

Chow, N.W.S. and Chi I. 1997. Ageing in Hong Kong, In: Lam, S.K., Editor, The health of the elderly in Hong Kong. Hong Kong University Press, Hong Kong, p.173-192.

Codispoti, C.L. and Bartlett B.J. 1994. Food and Nutrition for Life: Malnutrition and Older Americans. Report by Assistant Secretary for aging, Administration on Ageing, U.S. Department of Health and Human Services, Centre; NAIC Accession Number 02664.

Duraiswamy, P. 1998. Morbidity in Tamil Nadu: Level, differentials and determinants. Economic and Political Weekly, 33(17): 982990.

Ensrud, K.E., Duong T. and Cauley J.A. 2000. Low fractional calcium absorption increases the risk for hip fracture in women with low calcium intake: study of Osteoporosis Fractures Research Group. Ann Intern Med, 132: 345-353.

Fraser, S., Bunce C., Wormald R. and Brunner E. 2001. Deprivation and late presentation of glaucoma: Case-control study. British Medical J, 322: 639-643.

Frongillo, E.A., Chowdhury N., Ekstrom E. and Naved R.T. 2003. Understanding the Experience of household food insecurity in Rural Bangladesh leads to measure different from that used in other countries. The Am. Soc. Nutr. Sci., 133: 4158-4162.

Furness, B.W., Simon P.A., Wold C.M. and Anderson J.A. 2005. Prevalence and predictors of food insecurity among low-income households in Los Angeles country. Public Health Nutr., 7(6): 791-794.

Gulliford, M.C., Mahabir D. and Rocke B. 2003. Food insecurity, food choices, and body mass index in adults: nutrition transition in Trinidad and Tobago. International J. Epid., 32: 508-516.

Household Income and Expenditure Survey (HIES). 2005. Bangladesh Bureau of Statistics, Ministry of Planning, Peoples Republic of Bangladesh, Dhaka, Published - 2007

Kabir, Y., Shahjalal H.M., Saleh F. and Obaid M. 2010. Dietary pattern, nutritional status, anaemia and anaemia-related knowledge in urban adolescent college girls of Bangladesh. J.Pakistan Med. Ass., 60(8): 633-638.

Khaw, K.T. 1997. Healthy ageing. British Med. J., 315: 1090-1096.

Klesges, L.M., Pahor M., Shorr R.I., Wan J., Williamson J.D. and Guralink J.M. 2001. Financial difficulty in acquiring food among elderly disabled women: Results from the women's health and aging study. Am. J. Public health, 91(1): 68-75.

Kutty, V.R. and Thankapoan K.R. 1994. Morbidity Profile in Kerala with respect to Age, Education, Gender and Income, International Congress on Kerala Studies, Abstracts, AKG Centre for Research Studies, Thiruvanthapuram, India, 27-29 August, 9p.

Melzer, D., B. McWillams C., Brayne T., Johnson T. and Bond J. 2000. Socioeconomic status and the expectation of disability in old age: Estimates for England. J. Epid. Comm. Health, 54: 286-292.

Mostofa, G and van Ginneken J.K. 2000. Trends in and determinants of mortality in the elderly population of Mattlab, Bangladesh, Social Sci. Med., 50: 763-771.

Natarajan, V.S., Ravindran S., Thyagarajan S., Kailish K. and Krishnaswamy B. 1993. Assessment of nutrient intake and associated factors in an Indian elderly population. Age Ageing, 22: 103-8.

Olayiwola, I.O. 2009. Food consumption pattern and micronutrient intake of elderly Yorubas in Southwest Nigeria. Middle East $J$ Age and Ageing, 6 (4): E-mail: ibisumbo@yahoo.com 
Olson, C.M. 2006. Food insecurity in poor rural famlies with children: A human capital perspective, Policy Brief - March 2006, Division of Nutritinal Sciences, Cornell University.

Pilloni, A., Devos S. and Pelaez M. 2000. Ageing in Latin America and the Caribbean. Draft manuscript..

Rake, K. 1999. Accumulated disadvantage? Welfare state provision and the incomes of older women and men in Britain, France and Germany. In: Clasen, J., Editor, 1999. Comparative social polity: Concepts, theories and methods, Blackwell Publishers, Oxford, pp. 220-245.

Saleheen, M.U. 2005. Ageing: A creeping problem for future society? The Daily Star, July 6, 2005.

Schlettwein-Gsell, D. 1989. Dietary assessment of nutritional intake. In: Horwitz A, Macfayden DM, Munro H et al., eds. Nutrition in the Elderly. Oxford: Oxford University Press/WHO: 33-46.

Seabra, S.M. 2007. Paulo portraits: ageing in a large metropolis, International J. Epid., 37(4): 721-723.

Sun, W., Watanabe M., Tanimoto Y., Shibutani T., Kono R., Saito M., Usuda K.and Kono K. 2007. Factors associated with good self-rated health of non-disabled elderly living alone in Japan: a cross sectional study. BMC Public Health, 7: 82-97.

Williams, T.F. 1996. Geriatrics: Perspective on quality of life and care for older people. In: Siker, B., Editor, 1996. Quality of life and pharmacoeconomic in clinical trials, Lippincott-Raven Publishers, Philadelphia, 803-807. 